\title{
Diego Garcia
}

National Cancer Institute

\section{Source}

National Cancer Institute. Diego Garcia. NCI Thesaurus. Code C123746.

An atoll and the largest of 60 small islands comprising the Chagos Archipelago. 